\title{
Research on charging pile construction pattern for Communication scenarios
}

\author{
Xiaohui $\mathrm{XU}^{1, \text { a }}$, Yirong $\mathrm{SU}^{2, \mathrm{~b}}$, Yangyang $\mathrm{XI}^{2, \mathrm{c}}$, Jinsong $\mathrm{LIU}^{3, \mathrm{~d}}$, Hongchun YAO${ }^{1}$, \\ ${ }^{1}$ China Electric Power Research Institute, Renewable Energy Department, Nanjing, China \\ ${ }^{2}$ State Grid Electric Power Research Institute, Nanjing, China \\ ${ }^{3}$ State Grid Shanghai Municipal Electric Power Company, Shanghai, China \\ aemail: xuxiaohui@163.com, ${ }^{\mathrm{b} e m a i l: ~ s y r @ 126 . c o m, ~}{ }^{\mathrm{C} e m a i l}$ xyy@163.com, ${ }^{\mathrm{a}} \mathrm{email}$.jsl@163.com, \\ eemail: yaohongchun@163.com,
}

Keywords: electric vehicle, AC Charging Pile, Commercial operation mode, distribution network planning.

\begin{abstract}
In allusion to the increasing demand of electric vehicle, the elements that the AC charging pile construction which can adapt to multiple scene application is required to follow has been proposed through the analysis of the electric vehicle charging user's demand characteristics under different scenarios, and influencing factors such as electric vehicle charging technology, power distribution network planning and commercial operation mode. At last, it has been verified that the AC charging pile under above mode can guide the user to charge orderly, lower the charging cost and reduce the peak and valley difference of the power grid, etc.
\end{abstract}

\section{Introduction}

Electric vehicle is as one of the main development directions of new energy cars has gained more and more people's attention. With the electric car market tenure increasing, we must put forward the goal of building charging facilities, so as to provide the most fundamental support for the rapid development of electric vehicle. The quantity, layout, the model of $\mathrm{AC}$ charging pile construction is the key to the rapid development of electric vehicle and rapid commercial application will have important influence on electric vehicle application scope and scale development, so the construction of AC charging piles is particularly important.

Electric vehicle AC charging pile refers to a special power supply device that is fixed installed outside the electric vehicle, connected with the AC power grid, using car charger for electric vehicles to provide $\mathrm{AC}$ power of conduction modes, which is mainly applied to electric passenger vehicles charge[1]. A design scheme of electric vehicle AC charging pile construction is introduced in the document [2], which is applied to a batch of residential areas in Shenzhen City. The document [3-6] introduces the developing situation of the electric vehicle charging stations in our country and puts forward the influencing factors that affect the charging station planning of electric vehicle and planning principle, the optimal distribution and scale of research of electric vehicle, etc.

In this paper, the elements that the AC charging pile construction which can adapt to multiple scene application is required to follow has been proposed through the analysis of the electric vehicle charging user's demand characteristics under different scenarios, and influencing factors such as electric vehicle charging technology, power distribution network planning and business mode, it has been verified that the AC charging pile under above mode can guide the user to charge orderly, lower the charging cost and reduce the power grid peak valley through a city electric vehicle charging example. 


\section{Analysis on influencing factors}

The overall demand of electric vehicle charging amount. The overall demand of the electric vehicle charging is the key factor to influence the distribution of $\mathrm{AC}$ charging pile. Only after the charging quantity reaches a certain scale, the construction of $\mathrm{AC}$ charging pile can achieve mass distribution. Electric vehicle charging quantity is related to some factors such as electric vehicle ownership, the average daily driving mileage of the vehicle and level of energy consumption per unit mileage and so on.

Operation mode of multiple scenarios. Electric cars have different requirements for its battery life and charging time under the different operation mode of scenarios, which affect the charging mode and power consumption, and the construction mode of AC charging pile and power demand will also be directly affected. Electric vehicles can be divided into the demonstration area of car, group car, social vehicles, etc, according to the different user's type, the daily power consumption, travel route, routine, charging time of each type of vehicles are not identical, their own characteristics need to be considered that have effects on AC charging pile construction.

Effects of the business operation mode. One of the important indicators of the AC charging pile construction mode is reasonable or not is commercial operation, which includes construction cost, charging cost, operational safety and ability of AC charging pile, charging interface standards, benign development policy of charging pile, etc. Not only to consider the cost of the power grid reconstruction, land acquisition, environmental governance, etc., but also to consider social benefits after the construction of the ac charging pile. Ac charging pile construction at different sites, different size will directly affect the cost of charging the cost of the road and waiting, as shown in Fig. 1.

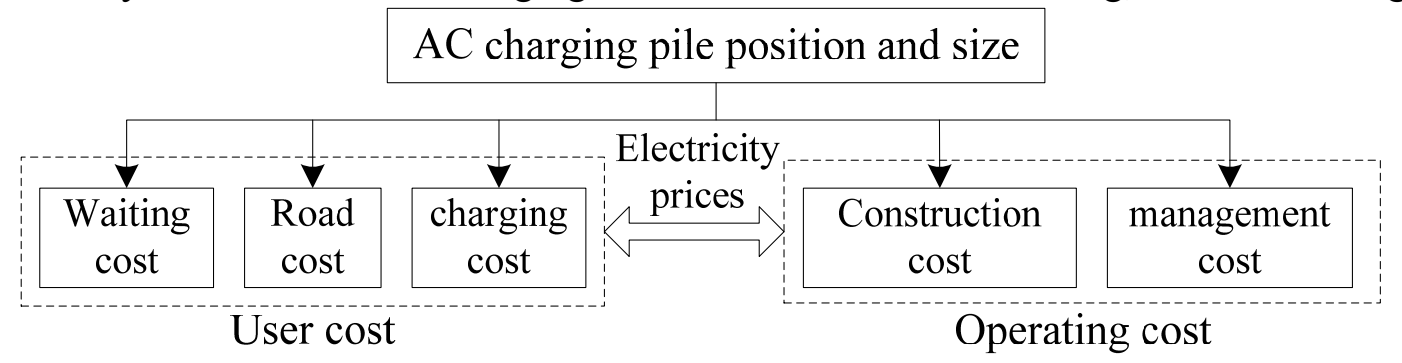

Fig. 1 The operation model relationship

As a result, the ac charging pile's location and size to determine charging must take into account the interests of both companies and users.

\section{Analysis on AC charging pile construction mode}

The mode we actually select in the construction of electric vehicle AC charging pile, that should focus on the core objective of "rapid, healthy and efficiently promote the development of electric vehicle industry and popularity, combine technical development trend and reality conditions for comprehensive considerations.

\section{Construction mode analysis of AC charging pile}

Layout rationality and requirements of charge service radius. The distribution of AC charging pile should be consistent with the flow density of electric vehicles and charging demand distribution, the number of $\mathrm{AC}$ charging pile network should be considered bringing into correspondence with charging demand distribution, and should be proportional to the density of the regional electric car flow.

The distribution of AC charging pile can refer to rules of gas station service radius in Code for Transport Planning on Urban Road issued by Ministry of Construction, and should be set according to the actual demand combined with the electric car's own operational characteristics and service radius calculated. Due to the various traffic density of different traffic district, service radius which reflects the AC charging pile network density varies too.

Regional distribution network present situation. The distribution of $\mathrm{AC}$ charging pile is the 
result of charge demand characteristic analysis in different places, The location shall be combined with the regional construction planning requirements, network settings shall be made by the comparison of the scheme of network layout and the surrounding area planning location, scientific planning arrangements of charging station construction layout shall be made according to the urban development planning and electric automobile popularization and application, and beware of duplication of investment and reduce the waste of investment.

Combined with filling station. AC charging piles construction planning should be combined with filling station already built, and consider the charging demand under multiple scenarios, and choose public areas such as parking lot of the company, public buildings (shopping malls, office buildings, etc.) and residential areas and special areas such as public transport, postal and other group teams to build the charging pile.

Full display of demonstrated application effect. It should adapt to the different stages of the popularization and application of electric vehicles. Since the current electric car industry is in the early stages of development, the demonstration effect of AC charging pile construction should be considered as a key factor, and when choose the construction sites, the commercial or residential areas which have bigger flow density should be mainly considered. Besides, it is necessary to promote the public understanding of electric vehicles and energy supply and improve corporate image of the State Grid Corporation.

Fully consider the future development trend of electric vehicles. With the strong promotion of the government, the considerable development shall be witnessed in the electric car industry. It should be given full consideration that the promotion effect of the application of electric vehicles for $\mathrm{AC}$ charging pile construction in the layout planning of $\mathrm{AC}$ charging pile, the planning should be forward-looking and global, and leave the potential to adapt to the requirements of the development of electric vehicles in the next few years. Electric car battery replacement technology can be divided into the trunk for electrical technology and chassis for electric technology.

\section{Computational example}

In accordance with the elements followed by the construction mode of AC charging pile, a district in Nanjing as an example, verifying the rationality of the construction mode. The area contains: a university town, an industrial park, two commercial districts, there were 500 electric cars shuttling between university city and residential area, 400 electric cars shuttling between commercial area and residential area, Additionally commercial district has 1500 times/day mobile vehicles, which also includes 1000 electric cars shuttling between residential area and other institutions (primary and secondary schools, hospitals, government agencies, etc). The computational example contains two kinds of charging mode: orderly guide charging (model A) and random charging (model B).
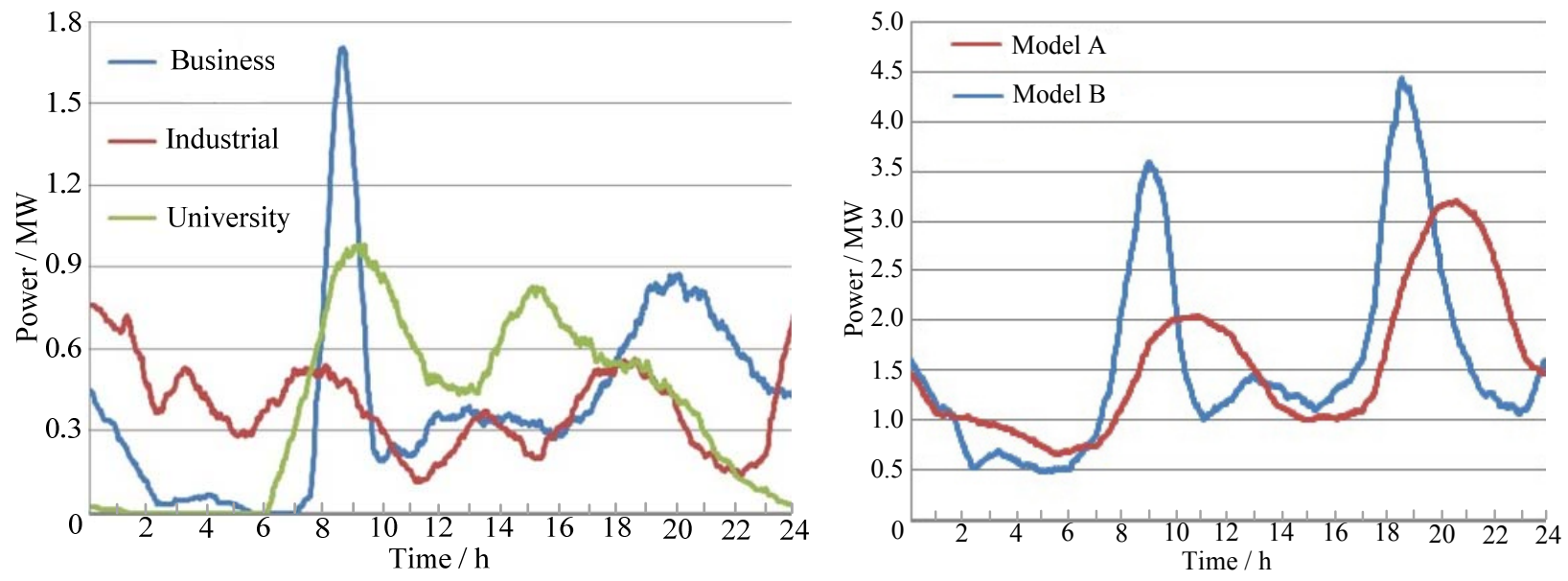

Fig. 2 EV charging daily load curve

Fig. 3 Two modes of EV charging characteristic curve

The simulation of charging power characteristic curve of the electric vehicle in orderly guide charging and random charging is shown in Fig. 3. The charging power curve of the mode A is more 
gradual than the curve of the mode $\mathrm{B}$, which indicates that orderly charging mode can reduce the peak and valley difference of the power grid load. In Fig. 4, the electric vehicle charging cost of orderly guide charging and random charging in three scenarios are analyzed. In the mode of orderly guide charging, charging cost dropped to the original $30 \%, 50 \%$ and $70 \%$ respectively.

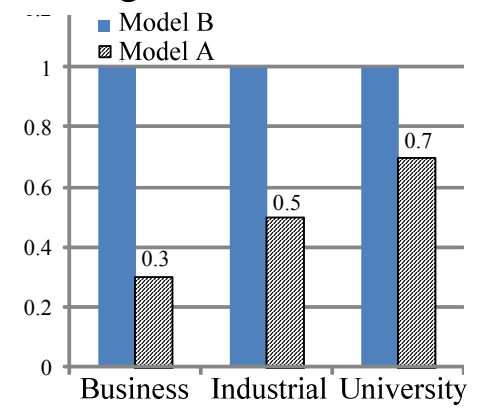

Fig.4 Two modes charge cost comparison

\section{Summary}

In this paper, based on the influencing factors of consideration such as electric vehicle charging characteristics under the multiple scenarios and electric vehicle charging technology, power distribution network planning, commercial operation mode, etc, we propose the elements that the AC charging pile construction which can adapt to multiple scene application is required to follow, according to that we make an electric vehicle classification and simulation verification in a district of Nanjing, the result of simulation shows that orderly charging mode can order charging behavior of the electric vehicle users, lower the charging cost and reduce the peak and valley difference of the power grid, etc.

\section{Acknowledgements}

This work was financially supported by China National science and technology support program projects funded projects (2013BAA01B04).

\section{References}

[1]Parks K, Denholm P, Markel T. Costs and emissions associated with plug-in hybrid electric vehicle charging in the Xcel Energy Colorado service territory, Technical Report, 2007, 5(13), pp.536-543.

[2]CHEN Jiangrong. The electric car ac charging pile construction design scheme, Electrical engineering technology, 2011, 6, pp. 23-24.

[3]KANG Jiguang,WEI Zhenlin, CHENG Danming, et al. Research on electric vehicle charging mode and charging stations construction, POWER DSM, 2009, 11(5), pp.64-66.

[4]REN Yulong, SHI Lefeng, ZHANG Qianqian. Optimal distribution and scale of charging station for electric vehicles, Automation of Electric Power Systems, 2011, 35(14), pp.53-57.

[5]E Pardo. Modeling of AC loss in coils made of thin tapes under DC bias current, IEEE Transactions on Applied Superconductivity, 2014, 24(3), pp.1-5.

[6]P Fan, B Sainbayar, S Ren. Operation analysis of fast charging stations with energy demand control of electric vehicles, IEEE Transactions on Smart Grid, 2015, pp.1-8. 